is one thing, while to create exclusion is another. Or is there a mediation between enunciating and constituting reality? By enunciating does one not enunciate what is al ready constituted, albeit still not revealed or visible? What relationship does the author see between the word and the thing, the "symbolic efficacy of constituting reality"? This would be a rich field for further exploration by Peterson's talent, since it is the paper's central hypothesis.

\section{An 'open' reading}

The paper is based on a proposal which could be summed up as follows, with the advantage of adding another reading to it: the scientific and deontological discourses, although constitutive, are not sufficient to express the totality of medical ethos. According to the proposal, another semantic field (amongst others not cited), that of 'medical slang', is capable of expressing this ethos in a less orthodox and more sensitive way, while also serving as one of its fields for creating new meanings. That is, this ethos is expressed in the relations between physicians themselves, physicians and patients, in the acquisition of new clinical knowledge, and in the relationship to the health system itself.

Based on this investigative wager, the irreducible conflict between the context of medical 'deprofessionalization'; the dismantling of health care services and the health 'utopia' (in the sense of a guiding set of ideals); lack of resources; and aggravation of social iniquities, far from constituting a mere backdrop, hologrammatically permeates the daily routine of these professionals and the medical ethos. Its field of specificity for each concrete social relationship (physician-physician, physician-patient, in the acquisition of new clinical knowledge, and vis-à-vis the health care system itself) needs to be detailed in appropriate studies and in a creative way, to draw out daily life, experienced circumstances, and the marks of use, as described by Certau (1994:82), [translated from the Portuguese version into English - T. n.] “(...) the ways by which utensils, proverbs, or other discourses are marked by uses; presenting for analysis the marks of acts or processes of enunciation (...) in a broader way, thus indicating a social historicity in which representational systems or constructi ve procedures no longer appear merely as normative frames, but as tools that can bemanipulated by users".

The constitution of new meanings thus occurs in a metaphorical field, of linguistic exchanges, as in a field of social exchanges, of conflict, of the search for prestige and legitimization amongst peers. In other words, the discourses produced by physicians for patients and health care institutions occur in different contexts of experiences and based on a logic of relationship between symbolic forces.

When the paper works so beautifully with the metaphor "The ICU is a torture room", it gives us a clue for understanding the creation of new meanings, whereby in the symbolic binomial 'torture room/ICU', torture adds meaning to the ICU, while the ICU adds a 'therapeutic' dimension to torture. Is a revealing representational dimension of this ethos insinuated (the need for torment and its legitimacy as therapy in 'extreme' cases)? When the physician calls public outpatient clinics mulambulatórios, is he not attempting to push the idea of mulambos away from his own self-image? After all, by 'treating' mulambos, and faced with the absolute inability to change their social and human reality, would such proximity not turn him into a mulambo, too? As the author suggests, these are clavicles/little keys in a symbolic archeology as rich as it is necessary: valuable subsidies for a discussion on trends in health ethics.

BOURDIEU, P., 1996. A Economia das Trocas Lingüísticas. São Paulo: Edusp.

CERTEAU, M., 1994. A Invenção do Cotidiano. As Artes deFazer. Petrópolis: Vozes.

\section{Sérgio Carrara \\ Language, social context, and 'etymological consciousness'}

Instituto de Medicina Social, Universidade do Estado do Rio de Janeiro Rio de Janeiro, Brasil.

Before making my comments, I should say that I am neither a linguist nor a specialist in jokes and puns. Thus, while my observations reflect my training in social anthropology, they may reflect more of a commonsensical view. They should thus be read as such. Christopher Peterson has published an interesting article on the slang, puns, and jokes used daily by Carioca physicians. The subject, as far as I know, has received little attention in Brazil. The article has the enormous disadvantage of being written in English, which hinders discussion of a theme which is linked to what are so often untranslat- 
able (as culturally impregnated), subtle meanings expressed by slang and jokes.

Contrasting his approach with that of Gordon in an article published in 1983 on hospital jokes for patients in California, the author attempts to distance himself from the sociological or socio-psychological theories according to which the main functions of physician slang and puns are the following: (1) to maintain a physician-patient distance; (2) to reinforce rapport among physicians; and (3) to relax the tension inherent to medical work. Although Peterson does not say so explicitly, such theories derive clearly from symbolic interactionism, as developed by H. Becker and E. Goffmann, among others. Therefore, this is the tradition he criticizes. Although referring indirectly to some of these theories, principally that which views jokes as relieving physician stress, Peterson considers them insufficient for understanding the role of jokes and puns in medical slang. Rather, he states, he attempts to demonstrate that jokes and puns create new meaning for the relations between physicians and patients, among physicians themselves, and between physicians and the health care system. According to the author, this capacity to create new meanings is linked to the fact that jokes and puns operate primarily through metaphors. Based on Richards and Ricoeur, the author incorporates the idea that, beyond illuminating the meaning of a given term by replacing or comparing it with another, metaphor alters the original meaning of both terms when it interrelates them. Rather than a 'substitutive' or 'comparative' view of metaphor, Peterson works with the idea of 'interactive' or 'creative' metaphor, extending this semantic capacity to jokes and puns. In addition, Peterson bases his analysis on Freud's idea that jokes or puns tend to occur in a context of conflictive relations, in which aggressiveness cannot be expressed in its raw, explicit, and direct form. And, as the author shows, there is no lack of conflict in the current Brazilian health scenario. The material comes basically from telephone and face-to-face individual or group interviews.

Having said this, I must confess that, although the article is original and daring, I felt uncomfortable with it on numerous points, on which I ask the author to comment. The first point relates to the lack of explicitness regarding the way the semantic and social planes are articulated. The problem becomes quite evident in the section focusing on jokes and puns for patients, when the author analyzes the expression mulambo. Although recognizing that physician jokes for patients sometimes have other origins, in the case of the expression mulambo the joke is seen as originating from the fact that the patient is perceived "as belonging to a lower soci oeconomic class". For some reason, which was not made clear, but which the author derives from Freudian theory, this perception causes an aggressive attitude on the part of physicians. Thus the humorous metaphor. Peterson states that by using the expression mulambo for poor and homeless patients, Carioca physicians are not only 'express'ing' the social exclusion to which such individuals are subjected, but by giving in to what appears to be an unconscious class aggressiveness, they are actively creating it. I find the idea reasonable as a hypothesis, but the way by which Peterson derives it from the theory of metaphor he adopts, presenting it to the reader as a conclusion from his study, is problematic, to say the least. Peterson states that, by approaching jokes for patients as a way of promoting rapport among the medical staff and maintaining their distance from patients, Gordon's approach "entails a substitutive view of metaphor..." and not the "creative metaphor" he prefers. What is lacking is a better explanation of why this occurs. Apparently, according to Peterson, since at the semantic level, metaphorical construction is a creative activity, ergo, use of the expression mulambo by Carioca physicians also creates exclusion, but now on a social level. To support this conclusion, Peterson states further that to there is other raw material other than patients to serve the functions Gordon ascribes to jokes. This is true, but it does not help me understand the relationship the author establishes between processes of social exclusion and the interactive theory of metaphor. I do not mean to defend physicians or much less the use of derogatory language for patients or anybody else. My problem is the confusion I see between an analysis performed on the linguistic plane and another occurring on the social plane. If Peterson had kept to the linguistic plane in his analysis of the expression mulambo, he would have to explain, as he did after all in the example "The ICU is a torture room" how the interactive metaphor mulambo changes the sense ascribed to the object mulambo (rag) and the street population metaphorized by it. But the author fails to do so. He changes levels suddenly and explains the creation of social exclusion by the use of mulambo in that the metaphor is creative on the semantic level. I fail to understand. In order to create social exclusion (or racial, as the author insinuates several times), physicians could use non-linguistic or non- 
metaphorical devices (like spending more time in consultation with wealthier or whiter patients). Linguistic activities like naming and classification, very much present in the diagnostic act, can be equally performative (partially creating that which they are supposed only to designate), without necessarily being metaphorical. Metaphor is creative at the semantic level, I have no doubt, but it can have multiple effects at the social level. In addition, in order to conserve, maintain, or reinforce social hierarchies, privileges, and inequalities, much creativity is needed at the semantic level. I thus fail to see how the premises lead to the conclusion in Peterson's reasoning.

In addition, in my opinion, the performative power of language can only be perceived through the social context of its concrete use (who speaks, why, and to whom). Words have no power in themselves, in fact they do not even exist outside of these contexts. And this leads me to my second area of discomfort: the almost total absence of social context in which these acts of speech occur (the author bases the analysis almost exclusively on interviews), where such observation would have been crucial. As I said above, the author sees in the use of certain jokes by physicians a class effect and also an racist effect, too, as he insinuates several times. I have no doubt that racial and class prejudice exist in Brazilian society as a whole and are manifested among physicians, especially at a moment in history when, as the authors point out quite properly, doctors are losing status and dangerously approaching that of their patients. I even believe that Brazil urgently needs more refined analyses on the way by which racial prejudice, especially, is reflected in medical practice. And Peterson's article has the merit of suggesting such analyses. However, according to the perspective he adopts, he fails to offer us a convincing analysis of the way by which the use of expressions like mulambo create class borders, much less racial ones. In order to achieve this, the author would have to abandon a purely textual analysis to demonstrate more clearly whether mulambo is used to describe poor people in general or only beggars (not that I think it would be more justified morally in the latter case). In fact, the contextual multivocality of the expression is even suggested by one of the physicians he interviewed, who recognizes that the use of the expression mulambulatório to refer to public outpatient clinics is extended improperly (in the interviewee's opinion) to all poor people, and adds, "but not all of them are really mulambos..." So who 'really' are the mulambos? This distinction is crucial, because if the doctors that use the expression are referring more specifically to beggars, then the meaning of the term may be that of criticizing the deplorable state in which a major portion of the Brazilian population lives. In other words, esmulambada [literally 'raggedy', from the same root as mulambo - T. n.] without being used metaphorically in this case. With regard to racism, which crops up several times in the article, the author would have to consider the way physicians treat white as compared to black poor people to determine whether the use of verbal language (not to mention the language incorporated into treatment and care) changes according to color or 'ethnicity' (as some would prefer it). The insinuation of racism based on the fact that the word mulambo has Bantu roots is untenable. The words caçula, cafuné, and bamba have the same roots and carry no negative connotation. Closer attention to the context might haveled the author to a more interesting analysis of such expressions as pitiático (which, by the way, he should have noted, refers clearly to hysteria), trubufu, and certain jokes referring to obese individuals. They suggest another line of social cleavage, neither that of race nor class, rather that of sex or gender, because they appear to focus primarily on women. In fact, I tried to find an equivalent term for trubufu for men, but could not. White men, even when they are ugly and fat, are not good joking material, contrary to homosexuals, blacks, bald men, and those currently seen as having erectile problems.

In short, the absence of a more sensitive approach to concrete social contexts in the use of speech has led the author to rely too heavily on etymology. And this leads me to my last source of discomfort. The article transpires the supposition of a certain 'etymological consciousness' on the part of speakers of a language. As if we all had an etymological dictionary installed in our brains. Of course the negativity of such Portuguese-language expressions as coitado [meaning the equivalent of "poor thing!" in English and deriving from the Latin coitus, thus reading literally as 'fucked' T.n.] or 'judiar' [deriving from judeu, i.e., 'Jew', meaning the equivalent of 'to torment, harass, etc.' or literally 'to treat as the Jews used to be treated' T.n.] bear the legacy of a chauvinist, racist society that one day placed such words in circulation. Brazilian society may not be much less chauvinist or racist today than it used to be. However, even if it were absolutely egalitarian, many people would continue to help the coitados and judiados without being 
suspected of vulgar language or anti-Semitism. The words have lost their original meaning. Thus, from my point of view, to find a trampolim in the trambique of the trambiclínicas from which to dive into the deeper meaning such terms have for physicians is risky and dangerous. As an allegory, the gesture is perfect, but as an analysis it is problematic. At any rate, I repeat, the author raises interesting questions which, from my point of view, deserve deeper analysis through other methods and materials. The text is daring, and I also see great merit in this sense. The issue is how not to let intellectual daring slip into analytical temerity.

\section{Daniela Riva Knauth}

Departamento de Medicina Social Universidade Federal do Rio Grande do Sul, Porto Alegre, Brasil.
The author's proposal to study the 'medical slang' used by physicians and heath care staff in daily clinical practice is quite innovative. Few studies have focused on this issue, although it calls the attention of the 'lay person' who has contact with the medical milieu. According to the common-sense view, such slang plays the role of maintaining a distance between the physician and patient and relieving tensions inherent to the profession, in constant contact with suffering and death. It also appears as a way of promoting rapport within the health care staff, through a complicity created by speaking the 'same language'.

The author does not accept these explanations and suggests that 'medical slang' can be seen as creating new meanings in physicians' relationship to: patients, clinical knowledge and specialization fields, and the health care system as a whole. He stresses the specificity of the Brazilian case he has studied, where such slang points to a kind of critique of the functioning of the health system, through such puns as trambiclínicas, pilantrópicos, mulambulatórios, and Embromed. As the author himself highlights, this critique is linked to physicians' discontentment towards the dependence of professional practice on different health plans and public policies.

Thus, although he points to these contextual variables, the author searches for the meaning of physician slang more in the etymological origin of the words forming the puns than in the position these physicians occupy in the medical field. Another contextual aspect overlooked by the author, and which might have led his analysis in a different direction, placing the critical nature of slang in a relative light, is the recurrence of the type of behavior it expresses in Brazilian society; here I am reminded of the work of Roberto Da Matta $(1983,1997)$ concerning the relationship of Brazilians to institutions, norms, and laws. The author's proposal of understanding 'medical slang' as an expression (albeit incipient) of the search for either a new ethic or an adjustment of medical ethical principles to the reality confronted by physicians would thus gain argumentative weight.

Another contextualization which I consider fundamental, and which is lacking in the article, refers to medical culture per se, i.e., the place and role of so-called medical 'slang' and metaphors in the construction and identification of the 'medical world'. Byran Good (1994), in analyzing how doctors construct their objects, states that learning medicine is similar to "learning a foreign language", not only because it involves learning specific scientific terms, but above all in learning a way of observing and describing which is proper to these professionals. In this sense, we might ask how these medical 'slang' terms and metaphors enter into this learning process? Do they express this particular way of viewing and describing the world of medicine? If so, they should not be viewed only through the etymological sense of the words that constitute them. The slang and metaphors used to designate relations between specialization fields, the different 'types' of patients, and the health plans and policies can be seen as ways physicians have learned to deal with these situations, reaffirming values and principles pertaining to the profession itself, and thus constructing a particular reality. In this context, the hospital and the outpatient service (along with their respective patients and staff) are a prime object of construction and expression of such representations.

DA M ATTA, R., 1983. Carnavais, Malandros e Heróis: para uma Sociologia do Dilema Brasileiro. 4th ed., Rio de Janeiro: Zahar.

DA MATTA, R., 1997. O que Faz o Brasil Brasil. 8th ed., Rio de Janeiro: Rocco.

GOOD, B., 1994. How medicine constructs its objects. In: Medicine, Rationality and Experience. (B. Good, ed.), pp. 65-87, Cambridge: Cambridge University Press. 